\title{
FLOW AT WORK: EVIDENCE FOR AN UPWARD SPIRAL OF PERSONAL AND ORGANIZATIONAL RESOURCES*
}

\begin{abstract}
The present 2-wave study among 258 secondary school teachers investigates the relationship between personal and organizational resources on the one hand, and work-related flow on the other hand. On the basis of Hobfoll's (1988) conservation of resources theory, Bandura' social cognitive theory (1997; 2001), and Fredrickson's (1998) "broaden-and-build" theory of positive emotions, we formulated two hypotheses: (1) personal resources (i.e., self-efficacy beliefs) and organizational resources (including social support climate and clear goals) facilitate work-related flow (work absorption, work enjoyment, and intrinsic work motivation); and (2) work-related flow has a positive influence on personal and organizational resources. The results of a series of structural equation modeling analyses offer clear support for both hypotheses. The theoretical and practical implications of these findings are discussed.
\end{abstract}

KEY WORDS: flow, organizational resources, personal resources, positive psychology, teachers.

\section{INTRODUCTION}

What is a good work life is a basic topic for workers and organizations nowadays, being of fundamental relevance for psychological research as well. Recently, Luthans (2002a, b) has noted the need for Positive Organizational Behavior (POB) research, defined as the study and application of positively oriented human resource strengths and psychological capacities that can be measured, developed, and effectively managed for performance improvement in today's workplace (Luthans, 2003, p. 179). Wright (2003) has argued that the mission of POB must also include the pursuit of

* This research was supported by a grant from the Bancaixa Foundation (\#11232.01/1) and the Spanish Ministry of Science \& Technology (CICYT \#SEC2000-1031). 
employee happiness and health as viable goals in themselves. The present two-wave study among school teachers will focus on the experience of flow at the workplace. We concur with Wright (2003) that the pursuit of flow is a viable goal in itself, and will examine its dependence on and value for the quality of employees' working environment. More specifically, the current study will examine whether personal and organizational resources facilitate flow at work, and whether employees who experience flow mobilize more resources over time.

\section{Flow at Work}

Csikszentmihalyi (1997, p. 29) has described the flow experience as: "one that many people have used to describe the sense of effortless action they feel in moments that stand out as the best in their lives." In this state, people are intensely involved in an activity and so nothing else seems to matter. In addition to the pleasure in the activity and the intrinsic interest to continue doing it, the total immersion in an activity seems to be a central aspect of the flow experience (Csikszentmihalyi et al., 1993; Ellis et al., 1994; Ghani and Deshpande, 1994; Larson and Richards, 1994). On the basis of these previous studies, Bakker (2005) applied the concept of flow to the work situation, and defined flow as a short-term peak experience at work that is characterized by absorption, work enjoyment and intrinsic work motivation. Absorption refers to a state of total concentration, whereby employees are totally immersed in their work. Time flies, and they forget everything else around them (cf. Csikszentmihalyi, 1990). Employees who enjoy their work and feel happy make a very positive judgment about the quality of their working life (cf. Veenhoven, 1984). This enjoyment or happiness is the outcome of cognitive and affective evaluations of the flow experience (cf. Diener, 2000; Diener and Diener, 1996). Finally, intrinsic work motivation refers to the need to perform a certain work-related activity with the aim of experiencing the inherent pleasure and satisfaction in the activity (cf. Deci and Ryan, 1985). Intrinsically motivated employees are continuously interested in the work they are involved in (Harackiewicz and Elliot, 1998). Employees who are motivated by the intrinsic aspects of 
their work tasks want to continue their work; they are fascinated by the tasks they perform (Csikszentmihalyi, 1997).

\section{Do Resources Lead to Flow at Work?}

Bakker's (2005) study among music teachers showed that organizational resources can be important antecedents of flow experiences among teachers and their students. He found that teachers working at schools with high levels of autonomy, social support, supervisory coaching, and feedback were most likely to experience flow at work. Demerouti et al., (2001) defined job resources as those physical, psychological, social, or organizational aspects of the job that either/or: (1) are functional in achieving work goals; (2) reduce job demands and the associated physiological and psychological costs; (3) stimulate personal growth and development. Examples of job and organizational resources are social support from colleagues, performance feedback, skill variety, job control, and supervisory coaching. These resources have motivational potential because they make employees' work meaningful, hold them responsible for work processes and outcomes, and provide them with information about the actual results of their work activities (cf. Bakker et al., 2003; Hackman and Oldham, 1980). Although we could not find other studies relating organizational resources to work-related flow, several recent studies have provided additional evidence for the motivational potential of resources. In their study among human service professionals (including consultants, nurses, and teachers), Bakker et al. (2004) have shown that resources foster work engagement, which, in turn, is predictive of (colleagues' ratings of) organizational citizenship behavior. Similarly, Bakker et al. (2003) have shown that production workers' organizational resources foster organizational commitment, which, in turn, causes reduced absence frequency. Furthermore, in a series of studies in several occupational settings, Salanova and her colleagues have shown that organizational resources can be important predictors of work engagement, which, in turn, is predictive of important organizational outcomes including service climate (Salanova et al., in press), and group performance (Salanova et al., 2003). Finally, Houkes (2002) included several job resources in her longitudinal 
research among bank employees and teachers, and found evidence for a causal relationship between the "motivating potential score" (an additive index, including skill variety, task identity, task significance, autonomy, and job feedback) and intrinsic work motivation. By contrast, a lack of organizational resources has a detrimental effect on workers' motivation and performance (e.g., Wong et al., 1998), since it precludes actual goal accomplishment, and undermines employees' learning opportunities (e.g., Kelly, 1992).

This latter reasoning is consistent with Conservation of Resources (COR) theory (Hobfoll, 1989, 1998, 2002). Accordingly, people seek to obtain, retain, and protect resources and stress occurs when resources are threatened with loss or lost, or when individuals fail to gain resources after substantive resource investment. Thus, COR-theory also places the acquisition and facilitation of resources as a central motivational construct. It is assumed that individuals seek to acquire and maintain resources, including objects (e.g., a home, clothes, food), personal characteristics (e.g., self-esteem), conditions (e.g., being married or living with someone who provides social support), and energies (e.g., time, money, and knowledge). However, the two principal types of resources that have been examined within the COR framework are personal and psychosocial resources (Hobfoll et al., 2003). The present study will focus specifically on self-efficacy (i.e., a personal resource), in addition to organizational resources.

Personal resources are aspects of the self that are generally linked to resilience. The best studied of these pertain to individuals' sense of their competence to successfully control and impact their environment (Hobfoll et al., 2003). Self-efficacy has shown its power as a buffer in stress processes, and it has also been related to better health, better self-development and greater social integration (Bandura, 1997, 1999, 2001). In addition, there is considerable evidence regarding the positive effects of self-efficacy on performance and well-being in different domains such as the workplace, school, and sports (Bandura, 1999, 2001). For example, research in the domain of work shows that high levels of efficacy beliefs have a positive impact on employee well-being (Grau et al., 2001) and work engagement 
(Salanova et al., 2003), and can buffer the negative impact of job demands on burnout (Salanova et al., 2000; 2002). According to Bandura $(1997,2001)$, efficacy beliefs contribute to motivation in several ways. Efficacy beliefs influence (a) the challenges people pursue, (b) the effort they expend, and (c) their perseverance in the face of obstacles.

So far, self-efficacy (as a personal resource) can be seen as one of the resources people want to protect (a very important one, which has received considerable research attention). The organizational resources we included are yet other examples of resources people are motivated to protect. In other words: all resources we studied are part of the resource reservoir people possess. This also means that COR theory can be seen as the overall framework we used for our study.

Therefore, we hypothesize that, in addition to organizational resources, self-efficacy beliefs may also enhance the experience of flow at work:

Hypothesis 1: Organizational resources (e.g., social support and clear goals) and personal resources (i.e., self-efficacy beliefs) have a positive influence on the experience of work-related flow (i.e., absorption, work enjoyment and intrinsic work motivation) (causation hypothesis)

\section{Does Flow at Work Lead to an Accumulation of Organizational and Personal Resources?}

Is it also possible that flow experiences lead to more organizational and personal resources? Some recent studies indeed found evidence for reversed causal relationships between organizational resources and employee psychological well-being. In her study among bank employees and teachers, Houkes (2002) found evidence for a reversed causal relationship between the motivating potential score and intrinsic work motivation. Furthermore, Wong et al. (1998) reported that time 1 job satisfaction predicted several organizational resources assessed at time 2 (2 years later), including autonomy, task identity, skill variety, task significance and feedback. In a similar vein, in a cohort study among a heterogeneous sample of Dutch employees, De Lange (2003) found a reversed causal relationship between job control and job satisfaction. 
Taken together, these findings suggest that work motivation and job satisfaction can both be outcomes as well as predictors of organizational resources, such that enhanced well-being results in more favorable organizational resources over time. This is consistent with Hobfoll's $(1989,2002)$ claim that because resources are valued either in their own right or because they enable the acquisition or preservation of other valued resources, people are motivated to create resources. Once resources are obtained, people are motivated to protect them. In addition, the hypothesis that flow at work may lead to more personal and organizational resources over time is consistent with Fredrickson's (1998, 2002) "broaden-and-build" theory of positive emotions. Accordingly, positive emotions broaden people's momentary thought-action repertories and build their enduring personal resources. Research has indeed shown that positive emotions such as joy, happiness, and interest have long-term adaptive benefits because broadening builds enduring personal resources including physical, intellectual, social and psychological resources (Fredrickson and Branigan, 2005; Fredrickson, 1998, 2001). Moreover, research with the broaden-and-build theory showed that momentary experiences of positive emotions can build enduring psychological resources and trigger upward spirals toward emotional well-being. Thus, positive emotions not only make people feel good at the moment, but also feel good in the future (Fredrickson and Joiner, in press). The current study will focus on the building effect (i.e., the second hypothesis in the theory). Accordingly, positive experiences (such as flow at work) build people's enduring personal resources. Indirect evidence consistent with this building hypothesis can be drawn from correlational and experimental studies that link positive states, traits and behaviors with physical, intellectual and social resources (Boulton and Smith, 1992; Bryan, Mathur \& Sullivan, 1996; Caro, 1988; Hazen and Durrett, 1982).

Furthermore, research on Social Cognitive Theory (Bandura, 1997, 1999, 2001) shows that experiencing positive emotions increases self-efficacy as a personal resource. When people judge their capabilities, they rely partly on bodily information conveyed by emotional states. According to Bandura, emotions are especially relevant when it comes to stress and health: negative 
mood diminished perceived efficacy, whereas positive mood enhances it. As is a tradition in psychological research, most studies investigated the impact of negative emotions (i.e., anxiety) on self-efficacy (Bandura, 1997). Studies relating positive states (including flow) to self-efficacy are sparse, but there is evidence showing that positive states influence self-efficacy, Salanova et al. (2002) showed that positive states at work such as enthusiasm, satisfaction and comfort influenced self-efficacy through work engagement in different occupational groups. Results indicated that the more positive experiences, the more engagement, which, in turn, predicted future self-efficacy.

On the basis of these theories and findings, we formulated our second hypothesis. The two hypotheses are graphically depicted in Figure 1.

Hypothesis 2: The experience of work-related flow (i.e., absorption, work enjoyment and intrinsic work motivation) has a positive influence on organizational and personal resources (reversed causation hypothesis).

\section{METHOD}

\section{Participants and Procedure}

A follow-up study with two waves was carried out among Spanish secondary school teachers. At the beginning of the

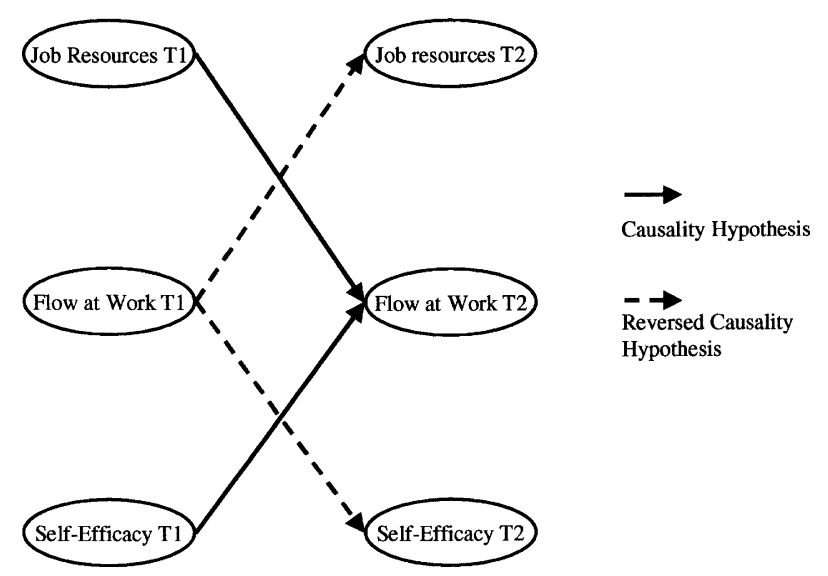

Figure 1. The upward spiral model of resources and flow at work. 
academic year, a letter was sent to 50 secondary schools explaining the goal of the research. Self report questionnaires including scales to measure the main variables of the current study plus other scales related to psychological well-being were distributed among 600 secondary teachers from these schools and were sent back through surface mail to the university. In total, 484 respondents from 34 schools returned the questionnaire ( $81 \%$ response rate). Eight months later, at the end of the academic year, identical questionnaires were distributed among the same schools. After deletion of missing cases, it turned out that 258 teachers (57\% women, $43 \%$ men) from 24 schools had completed both questionnaires, and their scores could be used in the longitudinal analyses. Thus, $57 \%$ of the teachers who participated at $T 1$ also participated at $T 2$. The mean age of the sample was 40 years $(\mathrm{SD}=7.01)$.

In order to test whether the drop-outs differed from the panel group, we compared the $T 1$ background variables of both groups (i.e., age, gender, type of school (private versus public), teaching experience, and organizational tenure). Results from ANOVAs and $\chi^{2}$ analyses showed that there were no significant differences between the groups regarding background variables. We therefore concluded that the panel group does not differ from the drop-outs in terms of background variables.

\section{Measures}

Organizational Resources were measured with the short version of the FOCUS Organizational Culture Questionnaire (González-Roma et al., 1995), including twelve items. Four resources were assessed with three items each, namely: (1) social support orientation or the extent to which there are kindly and supportive relationships among organizational members (e.g., "How many people with personal problems are helped?"), innovation orientation or the extent to which there is openness to new ideas and projects (e.g., "How many people are trying out new ways of working?"), rules orientation or the extent to which organizational members' behavior is regulated by formal norms and rules (e.g., "How often are jobs performed according to defined procedures?"), and goals orientation or the extent to which activities and behaviors are oriented towards the 
attainment of previously established objectives (e.g., "How often does management specify the targets to be attained?"). The answer categories ranged from 1("never/nobody") to 6 ("always/most of the people"). Cronbach's alpha of each scale is shown in Table I.

Personal Resources was measured as efficacy beliefs. It was measured with Schwarzer's (1999) 10-item generalized selfefficacy scale. However, consistent with social cognitive theory, the scale was slightly adapted for use in specific domain (i.e., the workplace, which is schools in our study). One example item is: "I will be able to solve difficult problems in my work, if I invest the necessary effort." The anchors ranged from 1 ("never") to 6 ("always"). Self-efficacy was included in the structural equation model as a latent variable, indicated by two reliable halves. Cronbach's alpha of the scales as measured at $T 1$ and $T 2$ is shown in Table I.

Flow at work was assessed with the WOrk-reLated Flow scale (WOLF; Bakker, 2001). The WOLF includes thirteen items measuring absorption (4 items), work enjoyment (4 items), and intrinsic work motivation (5 items). Examples are: "When I am working, I forget everything else around me" (absorption), "When I am working very intensely, I feel happy" (work enjoyment), and "I get my motivation from the work itself, and not from the rewards for it" (intrinsic work motivation). The participants were asked to indicate how often they had each of the experiences during the preceding week $(0=$ never, $6=$ every day).

\section{Data Analysis}

The data were analyzed with structural equation modeling techniques using the AMOS software package (Arbuckle, 1997). Each of the model components was included as a latent factor in the model, and was operationalized by the subscales introduces above as observed, indicator variables. Specifically, organizational resources was indicated by four variables (social support orientation, innovation orientation, rules orientation and goals orientation), flow at work was indicated by the three flow scales of the WOLF (absorption, work enjoyment, and 


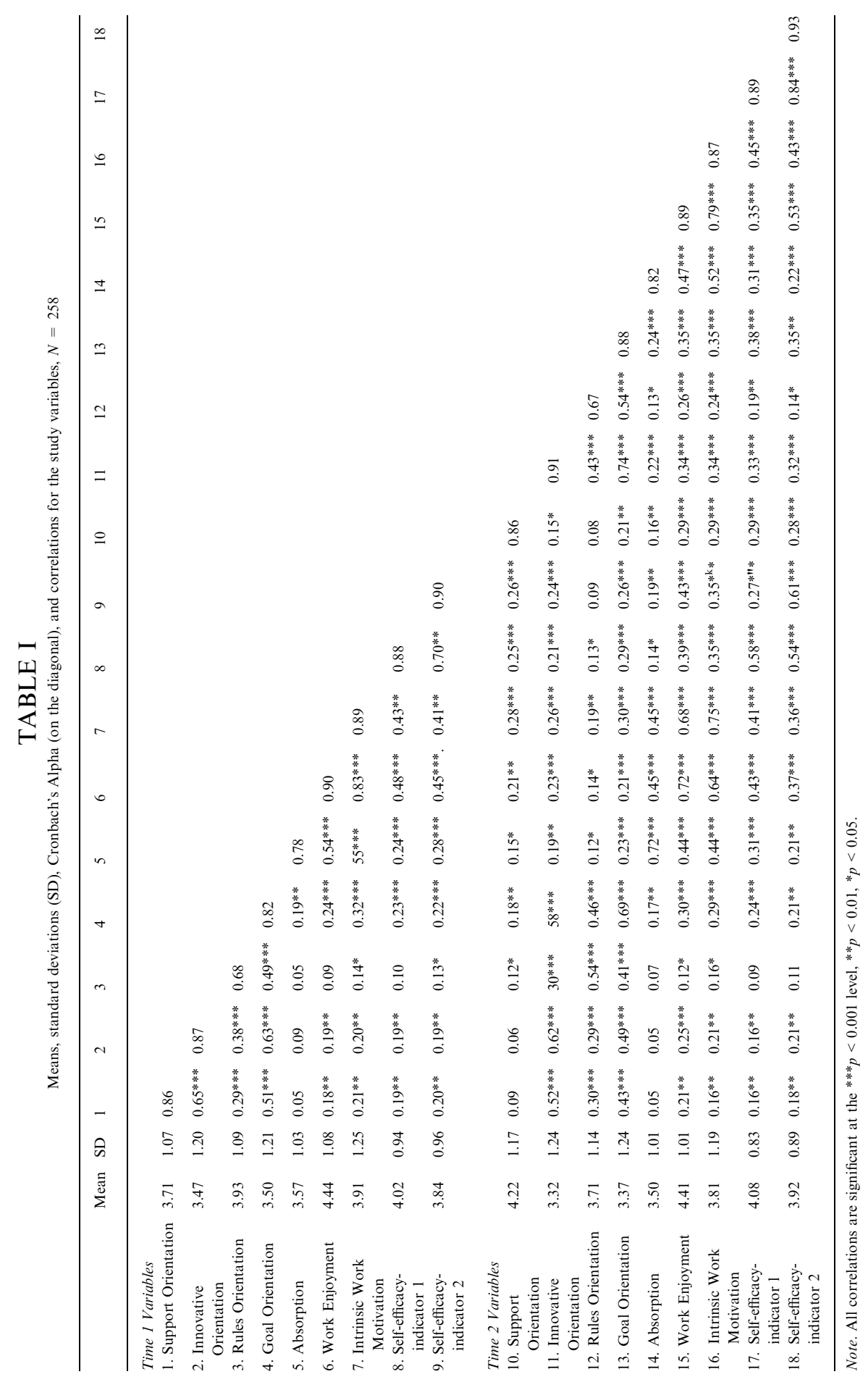


intrinsic work motivation), and self efficacy was indicated by two reliable halves of Schwarzer's modified scale.

A number of competing structural equation models were fitted to the data in several steps. First, a model without crosslagged structural paths but with temporal stabilities and synchronous correlations (Model 1) was specified. The temporal stabilities were specified as correlations between the constructs for each possible pair of measurement waves. This model estimates therefore the total stability coefficient between measurement waves 1 and 2, without decomposing the variance into constituent paths (direct and indirect effects) (see Pitts et al., 1996). Second, this stability model was compared with three more complex models that were nearest in likelihood to the hypothesized structural model: (a) Model 2: a model that is identical to Model 1 but also includes cross-lagged structural paths from Time 1(T1) organizational resources and $T 1$ personal resources to $T 2$ work-related flow. This model is the causality model; (b) Model 3: a model that is identical to Model 1 but also includes cross-lagged structural paths from $T 1$ flow to $T 2$ organizational resources and $T 2$ personal resources. This is the reversed causation model; (c) Model 4: a model that includes reciprocal relationships between organizational resources, personal resources, and work-related flow. This model includes all paths of Model 2 and 3, and is called the reciprocal model.

For all models, the measurement errors of the same indicators (i.e., subscales) collected at different time points were allowed to covary over time (e.g., a covariance is specified between the measurement error of work enjoyment as measured at $T 1$ and the measurement error of this scale as measured at T2). While in cross-sectional data measurement errors should generally not covary, in longitudinal measurement models the errors of measurement corresponding to the same indicator should covary over time. According to Pitts et al. (1996), this specification of covariance between errors of measurement accounts for the systematic (method) variance associated with each specific indicator.

The various nested models were compared by means of the $\chi^{2}$ difference test (Jöreskog and Sörbom, 1986). Besides the chisquare statistic, the analysis assessed the goodness-of-fit index 
(GFI) and the root mean square error of approximation (RMSEA), Furthermore, AMOS provides several fit indices that reflect the discrepancy between the hypothesized model and the baseline, Null model. In the present analyses, the comparative fit index (CFI) and the non-normed fit index (NNFI) are utilized. Marsh, Balla and Han (1996) recommended the latter two indices, because they are less dependent on sample-size than the $\chi^{2}$ statistic and the GFI. In general, models with fit indices $>0.90$ and RMSEA $<0.08$ indicate a good fit (Hoyle, 1995). Preliminary analyses showed that the demographics (included as covariates) were not systematically related to the model variables, and did not modify the results of the model testing. Therefore, to facilitate model estimation, the demographics were excluded from all further analyses.

\section{RESULTS}

\section{Descriptive Statistics}

Prior to the model testing, the means, standard deviations, Cronbach's alpha coefficients and bivariate correlations (including test-retest correlations) were computed (see Table I). As can be seen from the table, all variables had an alpha coefficient higher than 0.70 (with the exception of rules orientation which had an alpha coefficient of 0.68 and 0.67 at $T 1$ and $T 2$ ), and test-retest reliabilities of at least 0.54 . The highest testretest reliabilities resulted for self-efficacy followed by innovation orientation. This means that self-efficacy and innovation orientation are relatively stable over time.

\section{Model Testing}

Table II displays the overall fit indices of the competing models. In general, all models indicate a good fit since all fit indices are equal to or higher than 0.90 , the RMSEA is smaller than 0.08 , and the ratio between the $\chi^{2}$ statistic and the number of degrees of freedom is relatively low. We will first concentrate on the model comparisons.

The causality model (M2) proved to be superior to the stability model $(\mathrm{Ml})$, Delta $\chi^{2}(2)=35.29, p<0.001$. This suggests that 
the inclusion of cross-lagged paths from organizational resources and personal resources to flow is substantial. Additionally, the reversed causality model (M3) fitted significantly better to the data than the stability model, Delta $\chi^{2}(2)=33.49, p<0.001$. This indicates that the model with the cross-lagged path from $T 1$ flow to $T 2$ organizational resources and $T 2$ personal resources showed a better fit to the data than the model including only temporal stabilities and synchronous correlations (M1).

The $\chi^{2}$ difference test regarding the stability model vis-à-vis the reciprocal model (M4; see Table II) revealed that the addition of reciprocal effects significantly improved the stability model, Delta $\chi^{2}(4)=103.10, p<0.001$. Moreover, the model with the cross-lagged reciprocal relationships among the variables (M4) resulted in a significantly better fit to the data than the causality model (M2) and the reversed causality model (M3). The results of the $\chi^{2}$ difference tests for both comparisons (M2 versus M4 and M3 versus M4) are Delta $\chi^{2}(2)=67.81$, $p<0.001$, and Delta $\chi^{2}(2)=69.61, p<0.001$, respectively. This means that the theoretical model including cross-lagged reciprocal relationships between organizational resources, personal resources, and work-related flow fits best to the data.

We will now discuss the specific structural relationships that resulted from these models. First of all, it is important to note that all manifest variables loaded significantly on the intended

TABLE II

Goodness-of-fit indices for the alternative resources - flow models, $N=258$

\begin{tabular}{lllllllll}
\hline Model & $\chi^{2}$ & df & $p$ & & GFI & RMSEA & NNFI & CFI \\
\hline $\begin{array}{l}\text { M1. Stability Model } \\
\text { M2. Causality Model }\end{array}$ & 250.88 & 117 & 0.001 & 0.90 & 0.07 & 0.95 & 96 \\
$(\mathrm{JR}$, PR $\rightarrow$ Flow) & 215.59 & 115 & 0.001 & 0.91 & 0.06 & 0.96 & 0.97 \\
$\begin{array}{l}\text { M3. Reversed Causality Model } \\
\text { (Flow } \rightarrow \text { JR, PR) }\end{array}$ & 217.39 & 115 & 0.001 & 0.92 & 0.06 & 0.96 & 0.97 \\
$\begin{array}{l}\text { M4. Reciprocal Model } \\
\text { Null Model }\end{array}$ & 147.78 & 113 & 0.02 & 0.94 & 0.04 & 0.99 & 0.99 \\
& 3776.16 & 153 & 0.001 & 0.26 & 0.30 & - & - \\
\hline
\end{tabular}

Note: $\chi^{2}=$ chi-square; $\mathrm{df}=$ degrees of freedom; GFI = goodness-of-fit index; RMSEA = root mean square error of approximation; NNFI $=$ Nonnonmed fit index; CFI $=$ comparative fit index. $\mathrm{JR}=$ Job Resources, $\mathrm{PR}=$ Personal Resources. 
latent factors. Inspection of the output revealed that all indicators of organizational resources had loadings on the intended latent factor higher than 0.50 , both at $T 1$ and $T 2$. Furthermore, a both waves of measurement, the loadings of absorption, work enjoyment and intrinsic work motivation on the flow factor were higher than 0.67 , whereas the loadings of the two selfefficacy indicators were higher than 0.92. Second, the autocorrelations between the two waves were 0.71 for job resources, 0.60 for flow, and 0.47 for self-efficacy.

Hypothesis 1 asserted that job and personal resources would have lagged positive effects on work-related flow. The model that includes these causal relationships, the reciprocal model (M4), resulted in significant lagged, and positive effects of TI job resources on $T 2$ flow $(\beta=0.26, t=4.07, p<0.001)$, as well as a positive effect of $T 1$ personal resources on $T 2$ flow $(\beta=0.41, t=6.20, p<0.001)$. These findings clearly support our first hypothesis.

Hypothesis 2 stated that $T 1$ flow would have a lagged positive effect on $T 2$ organizational resources and on $T 2$ personal resources. The final reciprocal model also resulted in significant reversed causal structural relationships. Specifically, the relationships were as follows: $T 1$ flow $-T 2$ organizational resources $\beta=0.33(t=4.72, p<0.001), T 1$ flow $T 2$ personal resources $\beta=0.47(t=7.17, p<0.001)$. These findings clearly support our second hypothesis. Thus, the results from Model 4 (including the reciprocal relationships) showed that both causal and reversed causal relationships were simultaneously active. The significant paths of the reciprocal model are graphically displayed in Figure 2. The hypothesized predictors at TI explained $11 \%$ of the variance in $T 2$ resources, $28 \%$ of the variance in $T 2$ flow, and $22 \%$ of the variance in $T 2$ self-efficacy.

\section{DISCUSSION}

In the current study, the phenomenon of flow at work was investigated among teachers. The main research questions were whether flow is facilitated over time by the presence of personal and organizational resources, and whether flow has a positive 
influence on the availability of resources over time. In this study, flow was conceptualized as a short-term peak experience at work that is characterized by absorption, work enjoyment and intrinsic work motivation. Absorption refers to a state of total concentration, whereby employees are totally immersed in their work. Time flies, and they forget everything else around them. Enjoyment is a positive emotion of feeling happy and endorsing a very positive judgment about the quality of the working life. Finally, intrinsic work motivation refers to the need to perform a certain work-related activity with the aim of experiencing the inherent pleasure and satisfaction in the activity.

On the basis of a brief literature review, it was predicted that flow develops over time when personal and organizational resources are sufficiently available, because these positive characteristics foster flow experiences. In addition, we hypothesized a reversed causal relationship between resources and workrelated flow, i.e., that flow would predict future resources. The results of SEM-analyses - using a cross-lagged panel design

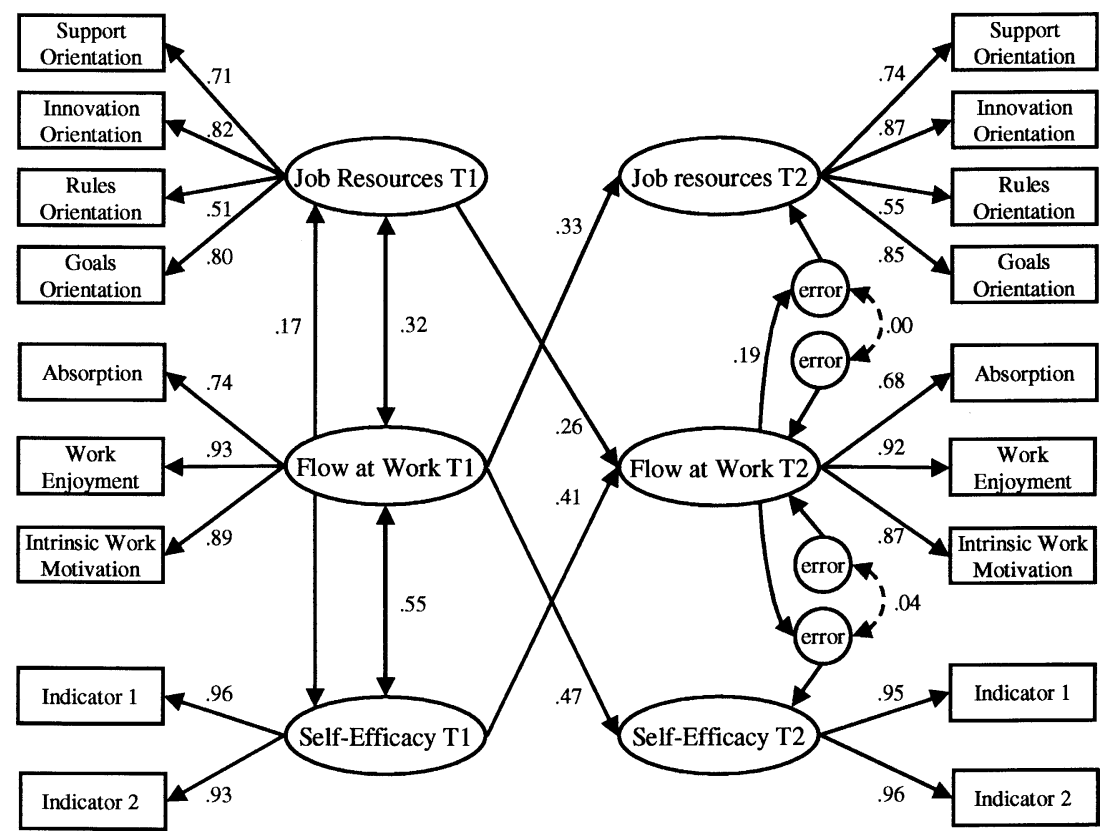

Figure 2. Standardized solution (maximum likelihood estimates) of the upward spiral model of resources and flow at work, $N=258$. 
( $N=258$ secondary school teachers) supported both hypotheses. More specifically, the results showed that the theoretical model including cross-lagged reciprocal relationships between resources and work-related flow fits best to the empirical data. This means that both causal and reversed causal relationships were simultaneously active in the reciprocal relationship between (organizational and personal) resources and work-related flow.

Organizational resources - a combination of different types of organizational climate orientation indicators such as social support (e.g., people help each other mutually, there are a good relationship between the co-workers), innovation (e.g., teachers can give suggestions to improve the quality of work, and they can put forward new ideas to improve the work), rules (e.g., the work that the teacher must do is plenty of norms and the decisions about the work process is made by the supervisors and goals, e.g., objectives are clearly defined) had a positive influence on the occurrence of flow among teachers over the time. Simultaneously, personal resources operationalized as strong beliefs about one's own competence at work - also fostered these flow experiences over time, So far, our first hypothesis was confirmed. These findings are consistent with previous research on the motivational power of resources at the work place (Bakker et al., 2003, 2004; Demerouti et al., 2002; Hackman and Oldham, 1980; Houkes, 2002; Salanova et al., 2003, 2004). Furthermore, the current study expands research on COR theory, showing that people seek to obtain, retain and protect resources in order to avoid stress and be psychologically healthy, including positive experiences (i.e., flow). COR theory evidences that the acquisition and facilitation of resources is a central motivational construct. In addition, this study also agrees with predictions from Social Cognitive Theory, which assumes that self-efficacy facilitates well-being (Bandura, 1997, 1999, 2003). In this sense, we found that self-efficacy is a powerful personal resource to build future positive experiences such as being immersed in one's work, to enjoy working, and to feel intrinsically motivated at work. Feeling competent in the present, seems to predict being in flow in the future. 
The second hypothesis was that the experience of flow (absorption, work enjoyment and intrinsic work motivation) has a positive influence on organizational and personal resources. Here and based on the literature, we assumed a reversed causal effect of work-related flow on organizational and personal resources. The results confirmed our hypothesis. More specifically, experiences of flow at work at the present influenced the gain of organizational and personal resources in the future. These findings are consistent with previous research on COR theory (Hobfoll, 1988), broaden-and-build theory (Fredrickson, 1998) and social cognitive theory (Bandura, 1997). For example, as resources are valuable in their own right, people in one way or another are motivated to create or increase their resources (Hobfoll, 1989, 2002), and positive experiences are powerful mechanism to increase and build organizational and personal (i.e., self-efficacy) resources over time (Bandura, 1997; Fredrickson, 2001). In our study, we found that flow as a positive experience at work influenced the organizational and personal resources among secondary school teachers over time. Furthermore, we found that flow predicted self-efficacy slightly more strongly than self-efficacy predicted flow. These results fit with what Hobfoll et al. (2003) found for sense of mastery as well.

Taken together, and perhaps even more interesting, our results showed that there exist reciprocal relationships between resources and flow. These results are supporting in a way the predicted upward spiral in which positive emotions are building resources that in turn influence positive emotions (Fredrickson, 2002). Findings of the current study showed that such positive work-related experiences as flow build organizational and personal resources, and that sometimes these positive experiences are reciprocally influenced by these resources.

\section{Study Limitations and Future Research}

A strong point of this study is its longitudinal character. Thus, the current findings can be framed in terms of cause and effect relationships because main variables are measured at different points of time, and we used several theories to formulate our hypotheses (Taris, 2000). However, we the results still need to be interpreted with some caution because of the non-experimental 
nature of this study. Another strong point is that the model explained an acceptable part of the variance in the dependent variables $(11 \%$ of the variance in $T 2$ resources, $28 \%$ of the variance in $T 2$ flow, and $22 \%$ of the variance in $T 2$ self-efficacy). However, a limitation of this study is that only teachers' self-reports were used in the examination of relationships between resources and flow. Here the problem of common method variance may have played a role. Because the study was conducted at 24 different schools, we could examine to what extent the flow experience per school was a function of the resources available at that school. Additional analyses showed that the scores on the flow dimensions absorption, work enjoyment and intrinsic work motivation were highest at those schools where many resources were available. These findings indicate that the subjectively reported resources were anchored in the objective working situation. Results thus offer specific starting-points for interventions aimed at mobilizing organizational resources and the promotion of flow experiences at schools.

Finally, this study is limited to the context of secondary school teachers. Since the main hypotheses were confirmed regarding reciprocal relationships between flow and resources, it would be interesting and relevant to examine this phenomenon in other occupational fields. In addition, it would be important to test the upward spiral model of these relationships using a cross-lagged panel design with more waves, in order to test the long time effects of these reciprocal relationships over time.

\section{Practical Implications}

It can be concluded that it is important for teachers to have sufficient resources available in their work. There are "good ingredients" of organizational culture such as social support, innovation, rules and goals orientation are examples of such organizational resources. When these resources are present in the organizational environment teachers are more likely to get engrossed in their work, to enjoy their work activities, and to be intrinsically motivated. They seem to form the basic ingredients of a "Good Working Life." As Nakamura and Csikszentmihalyi (2002) noted a good life is one that is characterized by complete absorption in what one does (p. 89). When 
work (re)design takes into account these organizational resources, there may be a good start, Job (re-)design seems to be a good organizational strategy to implement in schools in order to better teaching activities performance. On the basis of this job design, it is possible to optimize the working environment. On the other hand, feeling competent at work is other important (personal) resource to optimize at work. Our study showed once more the positive consequences of self-efficacy: the power of believing you can...

\section{REFERENCES}

Arbuckle J.L.: 1997, Amos users' guide. Version 4.0. Chicago, Ill: Smallwaters. Bakker, A.B.: 2001, Questionnaire for the Assessment of Work-related Flow: The WOLF (Department of Social and Organizational Psychology, Utrecht University, The Netherlands).

Bakker, A.B.: 2005, 'Flow among music teachers and their students: The crossover of peak experiences', Journal of Vocational Behavior 66, pp. 2644

Bakker, A.B., E. Demerouti, De Boer and W.B. Schaufeli: 2003, Job demands and job resources as predictors of absence duration and frequency, Journal of Vocational Behavior 62, pp. 341-356.

Bakker, A.B., E. Demerouti and W.B. Schaufeli: 2003, 'Dual processes at work in a call centre: An application of the Job Demands - Resources model', European Journal of Work and Organizational Psychology 12, pp. 393-417.

Bakker, A.B., E. Demerouti and W. Verbeke: 2004, 'Using the Job Demands Resources model to predict burnout and performance', Human Resource Management 43, pp. 83-104.

Bandura, A.: 1997, Self-efficacy: The Exercise of Control (Freeman, New York, NY).

Bandura, A.: 1999, Social cognitive theory of personality, in L. Pervin O. John (eds),Handbook of Personality 2nd edition, (Guilford, New York), pp. 154-196.

Bandura, A.: 2001, 'Social cognitive theory: An agentic perspective', Annual Review of Psychology 52, pp. 1-26.

Boulton, M.J. and P.K. Smith: 1992, 'The social nature of play fighting and play chasing: Mechanisms and strategies underlying cooperation and compromise', in J.H. BarkowL. Cosmides and J. Tooby (eds), The Adapted Mind: Evolutionary Psychology and the Generation of Culture (Oxford University Press, New York), pp. 429-444.

Bryan, R., S. Mathur and K. Sullivan: 1996, The impact of positive mood on learning, Learning Disabilities Quarterly 19, pp. 153-162. 
Caro, T.M.: 1988, Adaptive significance of play: Are we getting closer?, Tree 3, pp. $50-54$.

Csikszentmihalyi, M.: 1990, Flow: The Psychology of Optimal Experience (HarperCollins, New York).

Csikszentmihalyi, M.: 1997, Finding Flow: The Psychology of Engagement with Everyday Life (HarperCollins, New York).

Csikszentmihalyi, M., K. Rathunde and S. Whalen: 1993, Talented Teenagers: The Roots of Success and Failure (Cambridge University Press, New York).

Deci, E.L. and R.M. Ryan: 1985, Intrinsic Motivation and Self-determination in Human Behaviour (Plenum, New York).

De Lange, A.: 2003, Three types of causation and longitudinal research. APANIOSH conference, Toronto, Canada (March 2003).

Demerouti, E., A.B. Bakker, F. Nachreiner and W.B. Schaufeli: 2001, 'The job demands - resources model of burnout', Journal of Applied Psychology 86, pp. 499-512.

Diener, E.: 2000, Subjective well-being, the science of happiness and a proposal for a national index, American Psychologist 55, pp. 34-43.

Diener, E. and C. Diener: 1996, Most people are happy Psychological Science 7, pp. 181-185.

Ellis, G.D., J.E. Voelkl and C. Morris: 1994, 'Measurement and analyses issues with explanation of variance in daily experience using the flow model', Journal of Leisure Research 26, pp. 337-256.

Fredrickson, B.L. and C. Branigan: 2005, 'Positive emotions broaden the scope of attention and thought-action repertories', Cognition and Emotion 19, pp. 313-332.

Fredrickson, B.L., and T. Joiner: (in press), 'Positive emotions trigger upward spirals toward emotional well-being' Psychological Science.

Fredrickson, B.L.: 1998, 'What good are positive emotions?', Review of General Psychology 2, pp. 300-319.

Fredrickson, B.L.: 2001, 'The role of positive emotions in positive psychology: The broaden-and-build theory of positive emotions', American Psychologist 56, pp. 218-226.

Fredrickson, B.L.: 2002, Positive emotions, in C.R. Snyder and S. Lopez (eds), The Handbook of Positive Psychology (Oxford University Press, Oxford), pp. 715-730.

Ghani, J.A. and S.P. Deshpande: 1994, 'Task characteristics and the experience of optimal flow in human-computer interaction', The Journal of Psychology 128, pp. 381-391.

Grau, R., M. Salanova and J.M. Peiró: 2001, Moderating effects of self-efficacy on occupational stress, Psychology in Spain 5, pp. 63-74.

González-Romá V., S. Lloret and J.M. Peiró: April, 1995, The Measurement of climate: An abridged version of the FOCUS Questionnaire. 7th European Congress on Work and Organizational Psychology, Gyôr, Hungary.

Hackman, J.R. and G.R. Oldham: 1980, Work Redesign Reading (Addison Wesley, MA). 
Harackiewicz, J.M and A.J. Elliot: 1998, 'The joint effects of target and purpose goals on intrinsic motivation: A mediational analysis', Personality and Social Psychology Bulletin 24, pp. 657-689.

Hobfoll, S.E.: 1989, 'Conservation of resources: A new attempt at conceptualizing stress', American Psychologist 44, pp. 513-524.

Hobfoll, S.E.: 1998, Stress, Culture, and Community: The Psychology and Philosophy of Stress (Plenum, New York).

Hobfoll, S.E.: 2002, 'Social and psychological resources and adaptation', Review of General Psychology 6, pp. 307-324.

Hobfoll, S.E., R.J. Johson, N. Ennis and A.P. Jackson: 2003, 'Resource loss, resource gain and emotional outcomes among inner city women', Journal of Personality and Social Psychology 84, pp. 632-643.

Houkes, I.: 2002, Work and Individual Determinants of Intrinsic Work Motivation, Emotional Exhaustion and Turnover Intention. Doctoral thesis, Maastricht University. Maastricht, The Netherlands: Datawyse.

Hoyle, R.H.: 1995, The structural equation modeling approach: Basic concepts and fundamental issues, in R.H. Hoyle (ed.), , Structural Equation Modeling, Concepts, Issues, and Applications (Sage, Thousand Oaks, CA), pp. 115.

Jöreskog K.G. and D. Sörbom: 1986, LISREL User Guide Version VI (4th ed) (Scientific Software International Mooresville, I11).

Kelly, J.E.: 1992, Does job re-design theory explain job re-design outcomes?, Human Relations 45, pp. 753-774.

Larson, R. and M.H. Richards: 1994, Divergent Realities: The Emotional Lives of Mothers, Fathers, and Adolescents (Basic Books, New York).

Luthans, F.: 2002a, 'Positive organizational behavior: Developing and maintaining psychological strengths', Academy of Management Executive 16, pp. $57-72$.

Luthans, F.: 2002b, The need for and meaning of positive organizational behavior, Journal of Organizational Behavior 23, pp. 695-706.

Luthans, F.: 2003, Positive organizational behavior (POB): Implications for leadership and HR development and motivation, in R.M. Steers L.W. Porter and G.A. Bigley (eds), Motivation and Leadership at Work (McGraw-Hill/Irwin, New York), pp. 178-195.

Marsh, H.W., J.R. Balla and K.T. Hau: 1996, An evaluation of Incremental Fit Indices: A clarification of mathematical and empirical properties, in G.A. Marcoulides and R.E. Schumacker (eds), Advanced Structural Equation Modeling, Issues and Techniques (Lawrence Erlbaum, Mahwah, NJ), pp. 315-353.

Pitts, S.C., S.G. West and J.Y. Tein: 1996, Longitudinal measurement models in evaluation research: Examining stability and change, Evaluation and Program Planning 19, pp. 333-350.

Salanova, M., S. Agut and J.M. Peiró: in press, Linking organizational resources and work engagement to employee performance and customer 
loyalty: The mediating role of service climate. Journal of Applied Psychology.

Salanova, M., R. Grau, E. Cifre and S. Llorens: 2000, Computer training, frequency of use and burnout: The moderating role of computer self-efficacy, Computers in Human Behaviour 16, pp. 575-590.

Salanova, M, S. Llorens, E. Cifre, I. Martinez and W.B. Schaufeli: 2003, 'Perceived collective efficacy, subjective well-being and task performance among electronic work groups: An experimental study', Small Groups Research 34, pp. 43-73.

Salanova, M., S. Llorens, J.M. Peiró and W. Schaufeli: July, 2002, How Positive Emotions Predict Self-Efficacy Via Engagement: A Positive Occupational Psychology Framework (Symposium Job Engagement, 25th ICAP Congress, Singapore).

Salanova, M., J.M. Peiró and W.B. Schaufeli: 2002, 'Self-efficacy specificity and burnout among information technology workers: An extension of the job demands-control model', European Journal of Work and Organizational Psychology 11, pp. 1-25.

Schwarzer, R.: 1999, General perceived self-efficacy in 14 cultures. Self-efficacy assessment. http:/www.yorku.ca/faculty/academic/schwarze/world14.htm.

Taris, T.W.: 2000, A Primer in Longitudinal Data Analysis (Sage, Thousand Oaks, CA).

Van Muijen, J.J., P. Koopman, K. De Witte, G. De Cock, Z Susanj, F.D. Lemoine Bourantes, N. Papalexandris, I. Branyicski, E. Spaltro, J. Jesuino, J. Gonzalez das Neves, H. Pitariu, E. Konrad, J. Peiró, V. Gonzalez-Romá and D. Turnipseed: 1999, Organizational culture: The FOCUS questionnaire, European Journal of Work and Organizational Psychology 8, pp. 551568.

Veenhoven, R.: 1984, Conditions of Happiness (Kluwer, Dordrecht, The Netherlands).

Wong, C.S., C. Hui and K.S. Law: 1998, A longitudinal study of the job perception-job satisfaction relationship: A test of the three alternative specifications, Journal of Occupational and Organizational Psychology 71, pp. 127-146.

Wright : 2003, Positive organizational behavior: An idea whose time has truly come, Journal of Organizational Behavior 24, pp. 437-442.

Address for Correspondence:

MARISA SALANOVA

Department of Psychology

Jaume I University

Campus Riu Sec, s/n 12017

Castellón, Spain

E-mail: Marisa_Salanova@uji.es 